\title{
Determination of the critical span for a large-caving above a mined-out area
}

\author{
Haiying ${ }^{1,2, *}$, Fengyu $\operatorname{Ren}^{3}$, Yunfeng $\mathrm{Zhao}^{4}$ and \\ Sitong $\operatorname{Ren}^{3}$ \\ ${ }^{1}$ College of Resources and Environmental Engineering, \\ Wuhan University of Science and Technology, Wuhan, 430081, China \\ ${ }^{2}$ Post-Doctoral Research Center of River HBIS Co, Ltd, \\ Chengde, 050023, China \\ ${ }^{3}$ College of Resources and Civil Engineering, Northeastern University, \\ Shenyang, Liaoning, 110819, China \\ ${ }^{4}$ Xigang Dengta Mining Co Ltd, Liaoning, Liaoyang, 111300, China
}

An analytical model presented here was developed to determine the critical span for a large-caving that developed above the mined out area in Xiaowanggou Iron Mine. The model development is based on field observations measurements, examination of the characteristics of overlying rock masses, research on caving process and application of simple loading conditions in the gravitational field. Key input parameters were determined and utilized to predict the critical span for a large-caving. The difference between the predicted and measured values is less than $\pm 3 \%$. Results from the analytical model and field measurements have demonstrated that the proposed model can be used to predict the timing and crater location of large-caving and it forms the theoretical basis for mitigation of risk associated with a largecaving in a safe and economical manner.

Keywords: Arch theory, critical span, large caving, mined out area, subsidence.

IN underground mining areas, back caving of a mined out area that progressively collapses and quickly reaches the surface is defined as large-caving. Large-caving usually results in surface subsidence and possible air blasts.

With regard to caving mechanism and mitigation of associated risks, researchers from China and overseas generally assume that as the span of a mined out area increases, the overlying rock mass goes from the initial stage of caving to persistent caving and then continues to cave through to surface and expand laterally ${ }^{1}$. At the stage of initial caving, the span of the mined out area can be adjusted to control the height of caving in the overlying rock mass ${ }^{2-4}$. In persistent caving, the back arch of the zone that has caved becomes unstable and caving continues upward. It is common that when caving progresses close to the surface, the upper layer of rock mass up to tens of metres in thickness may collapse in a violent manner resulting in a crater on the surface ${ }^{5}$. Though large-caving is usually unpredictable, there are various signs before it actually occurs. Chronologically these signs include intensified ground movements, stress

\footnotetext{
*For correspondence. (e-mail: lihaiying@wust.edu.cn)
}

concentration-induced damages and fracturing noises ${ }^{6-11}$. At present, various techniques like International Space Station (ISS) seismic monitoring system ${ }^{12}$, real-time detection of ground movements, micro-seismic systems installed in overlying rock masses and GPS and total station survey systems installed on surface are applied for monitoring large-caving above the mined out area ${ }^{13-17}$. An aseismic zone of loosening of up to 50 to $70 \mathrm{~m}$ in height above the cave back is monitored ${ }^{12}$. Meanwhile, work on the critical span echoes the studies undertaken in coal industry, as also in metal mining ${ }^{18}$. Numerical modelling techniques such as the rock failure process analysis (RFPA) can also be applied to determine the critical caving span and predict the timing of a large-caving ${ }^{19}$. The collapse height of the working was found to be proportional to the span width in opencast coal mines ${ }^{20}$. Development of a cave-in in loose ground intersected by a cohesive bed was depicted and presented in an earlier study $^{21}$. The findings, from different perspectives, have provided valuable data in identification of precursors of large-caving process, understanding the process and the critical role of the span of a mined out area. They have also been used to guide developing risk mitigation measures in case a large-caving occurs.

However, there have been limitations to the accuracy and reliability of monitoring and response systems such as uncertainties in data acquisition, transmission and processing, and subjectivities in risk classification systems. Numerical modelling methods are yet to be accepted and routinely used by technical personnel in mines. Hence, most metal mines still apply the assumed caving angle to the mining boundary to determine the extent of surface subsidence. Though such an approach demarcates a large surface area which encompasses the likely location of large-caving and potential subsidence area, it leads to implementation of risk mitigation measures in an excessively large area and unnecessarily well before the actual event. It is a common feature that predicted largecaving does not occur for a long time ${ }^{18}$. Such prolonged periods result in people's indifference in taking precautions during farming on surface and monitoring underground. Consequently, a large-caving may become a disaster to the public or the mining company when it does occur. In order to minimize the consequences of a largecaving in a safe and economical manner, it is necessary to study the caving mechanism and its contributing factors and establish a simple and practical analytical model. By using this model and the production schedule, it should be possible to predict the location and timing of a largecaving for mitigation of potential hazards associated with the caving event.

To determine better the critical span of a large-caving above the mined out area, an analytical model is proposed and verified based on field observations and measurements of a large-caving event in the upper, middle and lower mining zones at Xiaowanggou Iron Mine with the 



Figure 1. Stress arch and its force equilibrium: $\boldsymbol{a}$, Stress arch; $\boldsymbol{b}$, Force equilibrium in the arch.



Figure 2. Horizontal thrust versus height of the load bearing arch.

understanding that back caving is closely related to the strength and geological conditions of the overlying rock mass and mining depth.

In underground metal mines, the rock mass above a mined out area caves in as the combined mining area expands, if no backfill or support is placed or installed. The cave-back normally takes the shape of an arch immediately, beyond which there is a band or a zone of overlying rock mass under stress concentration. This band or zone of high stresses is commonly referred to as a stress $\operatorname{arch}^{22,23}$. The caving process of mined out area is a continuous failure of an old stress arch and continuous formation of new stress arch. With the increase in the span of the mined out area, the arch becomes unstable and caving progresses upward resulting in an increase in the height of the caved zone. For convenient application in the production, the caving is simplified as in the shape of an arch. The calculation model of large caving is illustrated in Figure 1 where the stress consists of two components, i.e. uniform loading across the top middle point of the arch and weights of the two portions between the uniform loading and the arch. By assuming an unit thickness and considering moment equilibrium, the horizontal thrust $T$ in the top middle section is determined by the equation

$$
T=\gamma\left(\frac{H}{2 h}+\frac{1}{3}-\frac{\pi}{4}\right) l^{2},
$$

where $T$ is the horizontal thrust $(t) ; h$ the arch height $(\mathrm{m})$; $H$ the depth of the floor of the mining zone $(\mathrm{m}) ; \gamma$ the average unit weight of the overlying rockmass $\left(\mathrm{t} / \mathrm{m}^{3}\right) ; l$ is the half span of the mined-out zone (m).

From eq. (1), it is seen that $T$ is directly proportional to $l^{2}$ and increases quickly with the scaled span of the mined out area. When the stress in the top middle section of the arch exceeds the compressive strength of the overlying rock mass, failure begins in the top portion of the arch and caving is initiated. Also from eq. (1), it is clear that under given span and depth, the thrust $T$ decreases with increase in the arch height $h$ as shown in Figure 2. If caving were to continue, an essential condition is that the strength of the overlying rock should decrease.

Conceptual and numerical model of caving were developed by Kratzsch ${ }^{21}$ and Duplancic ${ }^{24}$. When caving reaches the near-surface layer, a large caving zone is generated. In metal mines, near-surface layer normally consists of weathered and Quaternary rock types which generally have much lower strength than the underlying layers. For the convenience of our discussion, weathered and Quaternary rocks are henceforth collectively referred to as the near-surface weak rock layer. Findings from 


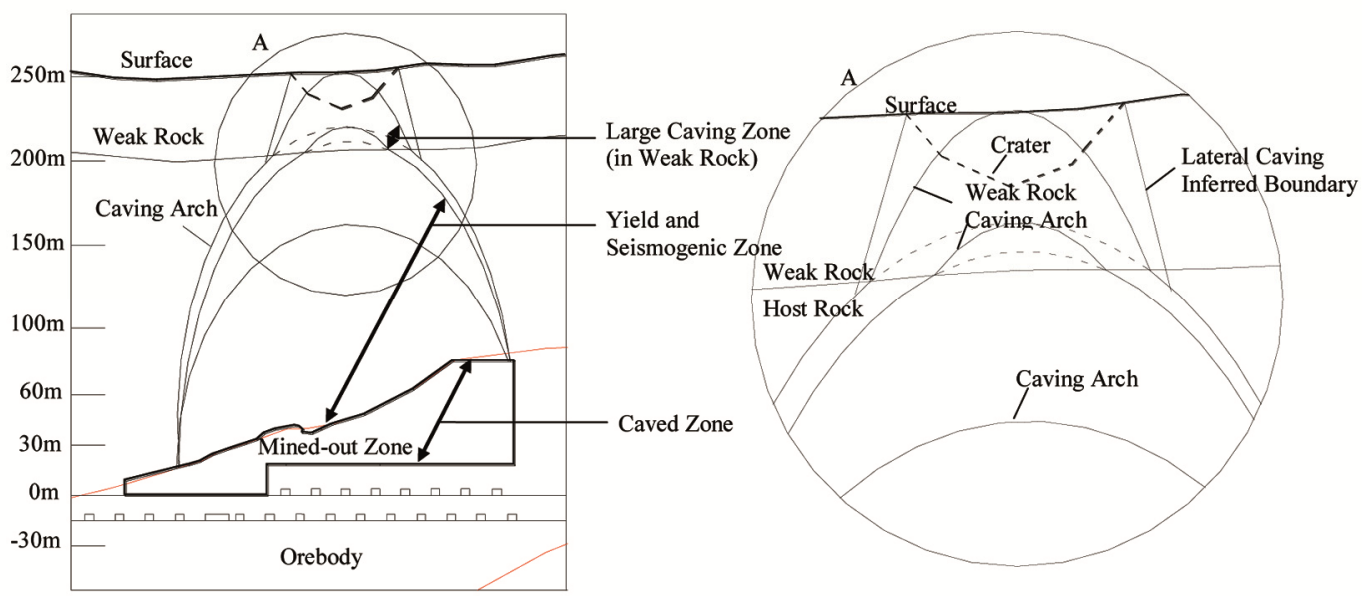

Figure 3. Schematic showing the caving process at Xiaowanggou Iron Mine.

(a)

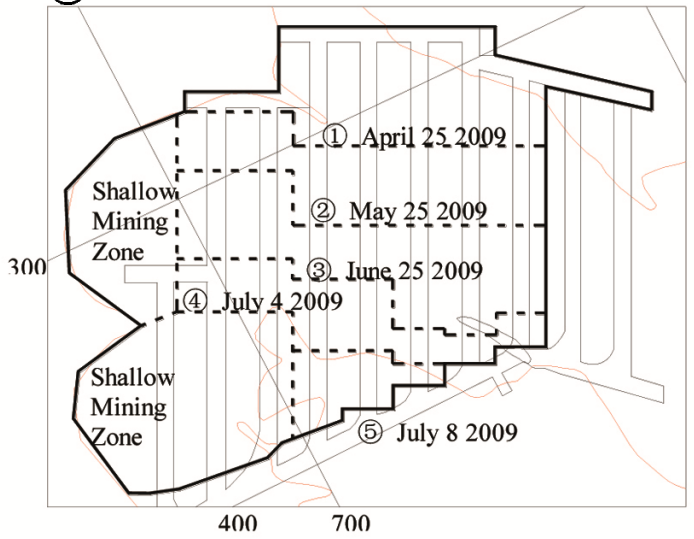

(b)



Figure 4. The upper mining zone and surface subsidence: $\boldsymbol{a}$, Schematic mining layout and sequence; $\boldsymbol{b}$, Crater on the pit wall resulted from large-caving.

various studies indicate that when caving arch reaches the near-surface weak layer, its curvature becomes sharper and height increases quickly. As the stress arch collapses, caving width in the weak rock masses expands leading to further caving above until a surface break occurs to acquire final stability as shown in Figure 3. In other words, stability of the stress arch cannot be maintained and caving propagates through to surface at a fast rate once the arch height reaches weak rock layer which is a prerequisite for large-caving to occur.

It is assumed that the overlying rock mass above the mined-out area is a continuum and its unidirectional compressive strength is $\sigma_{c}\left(\mathrm{t} / \mathrm{m}^{2}\right)$ and the effective thickness of the stress arch in the top portion is $d(\mathrm{~m})$. Therefore the horizontal thrust $T$ is determined by $T=\sigma_{c} d$. The arch height $h$ is equal to $H-h_{f}$, where $h_{f}(\mathrm{~m})$ is the thickness of near-surface weak rock layer. By substituting both expressions into eq. (1) and re-arranging the terms, the corresponding span $L_{j}(\mathrm{~m})$ defined as the critical span for a large-caving is determined by the following equation.

$$
L_{j}=2 \sqrt{\frac{12\left(H-h_{f}\right) \sigma_{c} d}{(10-3 \pi) \gamma H-(4-3 \pi) \gamma h_{f}}} .
$$

Here we present the application process, starting from selecting model input parameters to predicting the timing of a large-caving, based on observations and measurements in the lower mining zone at Xiaowanggou Iron Mine.

The mineralization at Xiaowanggou Iron Mine is that of a sedimentary-metamorphic magnetite deposit which has a thickness of 20-90 m, strike length of 400-800 m and a maximum extension of $400 \mathrm{~m}$ along dip with a dip angle of $15^{\circ}-35^{\circ}$. The overlying rock above the mining zone is conglomerate with an average unit weight $(\gamma)$ of $2.7 \mathrm{t} / \mathrm{m}^{3}$. The compressive strength of the intact rock is $55.80-78.50 \mathrm{MPa}$ with an average of $67.15 \mathrm{MPa}$. The thickness of the near-surface weathered rock is $36-48 \mathrm{~m}$ while that of the Quaternary layer is $8-20 \mathrm{~m}$. Total thickness of the weak rock layer is approximately $56 \mathrm{~m}$. The main structural surface of roof rock mass is stepped and 


\section{RESEARCH COMMUNICATIONS}


Figure 5. Cross section showing mined out stope in the middle mining zone and crater location when caving reaches surface: $\boldsymbol{a}$, Plan of $+240 \mathrm{~m}$ sublevel (mined first); $\boldsymbol{b}, \mathrm{A}-\mathrm{A}$ mining profile.

rough. The discontinuity spacing ranges between $0.25 \mathrm{~m}$ and $1.2 \mathrm{~m}$, average is $0.63 \mathrm{~m}$. Majority of the rock mass is hexahedral. A sublevel caving method is adopted in Xiaowanggou Iron Mine. In the sublevel interval, distance between cross cuts and blasting intervals in the upper and middle, and lower mining zones are as follows: (i) upper and middle zone (sublevel interval $=12 \mathrm{~m}$; distance between crosscuts $=10-12 \mathrm{~m}$ and each blast $=$ $15 \mathrm{~m}$ ) and (ii) lower zone (sublevel interval $=15 \mathrm{~m}$; distance between crosscuts $=18 \mathrm{~m}$ and each blast $=18 \mathrm{~m}$ ). Upper, middle and lower zones are simultaneously mined and all the three caved through to the surface independently by 10 September 2015 .

In the upper zone, a $+300 \mathrm{~m}$ sublevel was extracted from the hanging wall and both sides towards the footwall drive. Ore zone near the south boundary was mined using room and pillar method prior to retreating from east to west by drilling long holes in the crosscuts. Mining was started on 18 March 2009 and completed on 8 July 2009 and the mining sequence is shown in Figure $4 a$. When the retreating front reached line 4 on 4 July 2009 , the back of the mined out area caved through to surface and generated a crater on the pit wall as shown in Figure $4 b$ (ref. 19). Depth of the mined out zone corresponding to the centre of the crater was $45 \mathrm{~m}$ and after two $12 \mathrm{~m}$ benches of pit mining, actual thickness of the weak rock layer was approximately $32 \mathrm{~m}$. The span at the time of large-caving was estimated to be $69 \mathrm{~m}$ based on mining sequence and production schedule.

Mining in the middle zone was started in September 2008 and back caving reached the surface on 9 August 2012. During this period, six sublevels were mined from
$+240 \mathrm{~m}$ to $+180 \mathrm{~m}$ (Figure 5 ). As the mined out area was of an irregular shape, an equivalent diameter, defined as the diameter of the maximum circle that fits into the irregular shape projected on a horizontal plane, was used to represent the effective span. Depth of the mined out area was $126.5 \mathrm{~m}$ when large-caving occurred. The equivalent diameter for the mined out area was estimated to be $117.3 \mathrm{~m}$ based on surveyed mining fronts.

In the lower mining zone, a $+60 \mathrm{~m}$ sublevel was extracted first and production was started on March 2011. Since there was a mine road passing through the potential subsidence zone, caving progression was monitored via probing holes drilled near the road and also by regular inspection from accesses in the mining zone. In addition, we were also requested to provide an approximate timing of the large-caving so that the mine road could be rerouted in time.

The accuracy of predicting the timing of a large-caving depends on the quality of the model input data. There are five variables in eq. (2) where, the depth of the mined out area $H$, thickness of the near-surface weak layer $h_{f}$ and average unit weight of the overlying rock mass $\gamma$ can be determined through ground investigation and testing programs. However, it is difficult to determine the compressive strength of the overlying rock mass $\sigma_{c}$ and equivalent thickness in the top middle section of the stress (load bearing) arch $d$. Therefore both these parameters, required for a numerical analysis of underground excavations in rock, could be determined empirically. In this communication, they were estimated using Geological Strength Index (GSI)/Hoek-Brown method relying upon the empirical data from large-caving cases in upper 
and middle mining zones. The unidirectional compressive strength $\sigma_{c}$ is provided in the following relationship ${ }^{25,26}$

$$
\sigma_{c}=\sigma_{c i} s^{\alpha}
$$

where $s, \alpha$ are constants for the rock mass determined by GSI values which can be estimated based on the volumetric joint count $J_{\mathrm{v}}$ and the joint condition factor $J_{\mathrm{C}}$, and $\sigma_{\mathrm{ci}}$ is the uniaxial compressive strength of the intact rock. The joint condition factor $J_{\mathrm{C}}$ was arrived at as

$$
J_{\mathrm{C}}=J_{\mathrm{W}} J_{\mathrm{S}} / J_{\mathrm{A}}
$$

where $J_{\mathrm{W}}$ and $J_{\mathrm{S}}$ are the large-scale waviness (in meters from 1 to $10 \mathrm{~m}$ ) and small-scale smoothness (in centimeters from 1 to $20 \mathrm{~cm}$ ) and $J_{\mathrm{A}}$ is the joint alteration factor. Relying on the qualitative structure and joint condition in Xiaowanggou Iron Mine, 2.5, 2 and $1 \mathrm{~m}$ for $J_{\mathrm{W}}, J_{\mathrm{S}}$ and $J_{\mathrm{A}}$, $J_{\mathrm{C}}=2.5 \times 2 / 1=5($ refs 25,26$)$, the volumetric joint count $J_{\mathrm{V}}=3 / 0.63=4.76$, the value of GSI was estimated to be equal to 80 from the GSI lines on the $\operatorname{chart}^{27}$. When GSI was known, two constants $s$ and $\alpha$ in eq. (3) were obtained using the relation ${ }^{28}$

$$
\begin{aligned}
& s=\exp \left(\frac{\mathrm{GSI}-100}{9-3 D}\right) \\
& \alpha=\frac{1}{2}+\frac{1}{6}\left(\mathrm{e}^{-\mathrm{GSI} / 15}-\mathrm{e}^{-20 / 3}\right),
\end{aligned}
$$

where $D$ is a factor that depends on the degree of disturbance to which the rock mass has been subjected by blast damage and stress relaxation. $D$ factor was introduced in the latest update of Hoek-Brown failure criterion. When careful excavation techniques with controlled blasting are applied $(D=0)^{28}$, we have $s=2.22$ and $\alpha=0.5$. Substitution of $s, \alpha, \sigma_{c i}$ in eq. (3) yields

$$
\sigma_{c}=67.15 \times(\exp (-2.22))^{0.5} \approx 22.13 \mathrm{MPa}
$$

Based on the data from upper and middle mining zones in Xiaowanggou Iron Mine, the value of $d$ was tested from eq. (2) by using closely related factor and average discontinuity spacing. It was finally determined that three times of average discontinuity spacing will be the optimal value, viz. $d=3 \times 0.63 \mathrm{~m}=1.89 \mathrm{~m}$.

Based on the above discussion, $\sigma_{c}$ was calculated as follows

$$
\sigma_{\mathrm{c}}=22.13 \mathrm{MPa} \approx 2257.26 \mathrm{t} / \mathrm{m}^{2} .
$$

In the upper mining zone where $H=45 \mathrm{~m}, h_{f}=32 \mathrm{~m}$ and $\gamma=2.7 \mathrm{t} / \mathrm{m}^{3}$, the critical span was calculated to be $70.30 \mathrm{~m}$ which matched well with $69 \mathrm{~m}$ from the results of a scoping study at Xiaowanggou Iron Mine. The dis- crepancy was $+1.89 \%$. In the middle mining zone where $H=126.5 \mathrm{~m}, h_{f}=56 \mathrm{~m}$ and $\gamma=2.7 \mathrm{t} / \mathrm{m}^{3}$, the critical span was determined to be $119.16 \mathrm{~m}$ which was close to $117.3 \mathrm{~m}$ from the corresponding empirical background data; discrepancy was $+1.59 \%$. Error in both cases was less than the required accuracy of $5 \%$ for engineering design.

In the lower mining zone, critical span of a largecaving can be determined by using parameters $d=1.89 \mathrm{~m}$ and $\sigma_{c}=2257.26 \mathrm{t} / \mathrm{m}^{2}$ from our previous discussion. Once the critical span is known, timing of the large-caving can be predicted based on the production forecast and schedule. This approach is explained as follows: (1) Prepare a cross-section showing the progressive mining sequence in depth. (2) Measure the mining width $L_{i}$ and depth $H_{i}$ for each sublevel in the top down sequence as shown in Figure 6. (3) Calculate the critical span $L_{i j}$ corresponding to each mining step using eq. (2). (4) Compare $L_{i j}$ with $L_{i}$ and search for the first sublevel where $L_{i} \geq L_{i j}$. This is the sublevel where a large-caving would occur.

By using the steps listed above, the sublevel depth $H_{i}$ and mining width $L_{i}$ from Figure 6 and the calculated critical span for a large-caving ( $L_{i j}$ values) are tabulated in Table 1. It is seen that the mining width is greater than the critical span at $0 \mathrm{~m}$ sublevel. Therefore, it is inferred that a large-caving occurs once the mined out area on the $0 \mathrm{~m}$ sublevel is connected to the large voids above.



Figure 6. Prediction of the timing of a large-caving in the lower mining zone.

CURRENT SCIENCE, VOL. 116, NO. 4, 25 FEBRUARY 2019 


\section{RESEARCH COMMUNICATIONS}

Table 1. Calculation of critical span for each sublevel in the lower mining zone

\begin{tabular}{lccc}
\hline $\begin{array}{l}\text { Sublevel } \\
(\mathrm{m})\end{array}$ & $\begin{array}{c}\text { Sublevel } \\
\text { depth }(\mathrm{m})\end{array}$ & $\begin{array}{c}\text { Mining } \\
\text { width } L_{i}(\mathrm{~m})\end{array}$ & $\begin{array}{c}\text { Critical span for a } \\
\text { large-caving } L_{i j}(\mathrm{~m})\end{array}$ \\
\hline+60 & 192 & 60.08 & 157.80 \\
+45 & 207 & 89.28 & 164.57 \\
+30 & 222 & 152.61 & 170.82 \\
+15 & 237 & 173.49 & 176.61 \\
0 & 252 & 241.91 & 182.01 \\
\hline
\end{tabular}

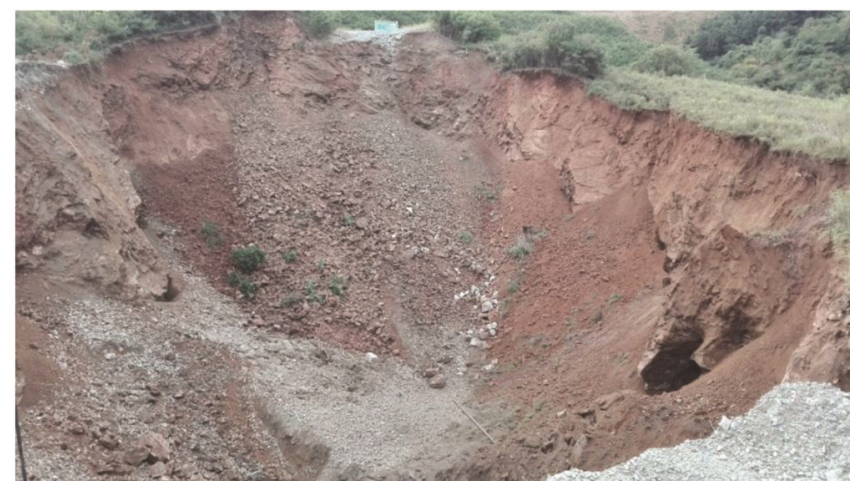

Figure 7. Crater or subsidence generated by the large-caving on 10 September 2015.

During the four sublevels mining from $+60 \mathrm{~m}$ to $+15 \mathrm{~m}$ period, the mined out area caved without being detected by underground personnel and it was observed from the 'Face End' of stopping roadways that the depth of collapsed debris was more than $30 \mathrm{~m}$. Yet a large scale caving event was not felt by the mine personnel until the $0 \mathrm{~m}$ sublevel of mined out area was connected to the voids above on 29 July 2015. Caving reached the surface 43 days later at $21 \mathrm{~h}$ on 10 September 2015 and a crater with a volume of $90,700 \mathrm{~m}^{3}$ was generated on the surface as shown in Figure 7.

The mining width on the $0 \mathrm{~m}$ sublevel did not change during the 43 days from the time of occurrence of the large scale caving to its breaking through to surface. The depth of the mined out zone corresponding to the centre of the surface crater was $245.6 \mathrm{~m}$ and the critical largecaving span was then calculated to be $179.75 \mathrm{~m}$ by using eq. (2), while the equivalent diameter of the mined out area was estimated to be $185 \mathrm{~m}$. The difference was $-2.84 \%$. This shows that the proposed analytical model for determination of the critical span for a large-caving satisfies the engineering requirement on accuracy and can be used to predict the timing of a large-caving. It also provides a basis for mitigation of risks associated with a large-caving in a safe and economical manner.

Some of the main conclusions are: (1) In mining, when caving arch reaches the near-surface weak layer and the mined out area has sufficient voids to accommodate the caved material, a large-caving reaching the surface is likely to occur. (2) The critical span for a large-caving above the mined out area can be determined using eq. (2) where the compressive strength of the overlying rock mass $\sigma_{c}$ is estimated based on the Hoek-Brown failure criterion. When this equation was applied to calculate the critical span in Xiaowanggou Iron Mine, it was found that the value of $d$ was three times the average discontinuity spacing and the difference between the calculated and measured values was less than $\pm 3 \%$ which satisfies the engineering requirement for accuracy. (3) It is seen that the proposed model for determination of critical span for a large-caving can be used to predict the progression timing of caving all the way up to the surface with the required accuracy. (4) Application of the proposed model enables mines to prepare for potential large-caving by the introduction and implementation of mitigation measures that minimize risks in a safe and cost effective manner. (5) However, there is a need for further testing of this model in other active mines to properly calibrate its accuracy so that its range of applicability can be defined better.

1. Li, Q. W., Ren, F. Y., Hou, J. G. and Li, J., Regularity of roof-fall in the southern worked-out zone of Xishimen Iron Ore Mine. China Min. Mag., 2001, 3, 44-46.

2. Zhou, Z. H., Ren, F. Y., Yuan, G. Q. and Ma, W. F., Application of induced caving technique in goaf treatment. Met. Mine., 2005, 12, 73-74.

3. Ren, F. Y., Li, H. Y., Ren, M. L., Liang, B. D. and Hu, F. Y., Technique of induced caving on adjacent mined-out areas in Shujigou Iron Mine. China Min. Mag., 2012, 1, 378-380.

4. Ren, F. Y., Han, Z. Y., Zhao, E. P. and Wang, W. J., Induced caving technique and its application in Beiminghe Iron Mine. Min. Res. Develop., 2007, 1, 17-19.

5. Zhao, W. and Ren, F., Prevention of rock falling and impact waves in a large-size connected mined-out area of dumbbell shape. China Min. Mag., 2000, 3, 79-82.

6. Szwedzicki, T., Geotechnical precursors to large-scale ground collapse in mines. Int. J. Rock Mech. Min., 2001, 38, 957-965.

7. Arvind, K. M., Awadh, K. M. and Manamohan, R., Blast-induced caving from surface over continuous miner panel at a $110 \mathrm{~m}$ cover in an Indian mine. Arab. J. Sci. Eng., 2013, 38, 1861-1870.

8. Wu, A. X., Wang, Y. M. and Hu, G. B., Air shock wave induced by roof falling in a large scale in ultra-huge mined-area. J. China Univ. Min. Technol., 2007, 4, 473-477.

9. Li, J. P., Xiao, X. F. and Feng, C. G., Progress in developing methods for dealing with Forsaken Stope. Chin. Saf. Sci. J., 2012, 3, 48-54.

10. Villegas, T. T., Nordlund, E. E. and Dahner, L. C. C., Hangingwall surface subsidence at the Kiirunavaara Mine, Sweden. Eng. Geol., 2011, 121, 18-27.

11. Gu, X. J., Study of mechanism of mine tremor due to falling-in by catastrophic theory. Chin. Saf. Sci. J., 2003, 10, 12-14+2.

12. Hudyma, M., Potvin, Y. and Allison, D., Seismic monitoring of the Northparkes lift 2 block cave - part I undercutting. J. South Afr. Inst. Min. Metall., 2008, 7, 405-419.

13. Jie, X., Jiang, J. D., Liu, Q. S. and Gao, Y. F., Stability analysis and failure forecasting of deep-buried underground caverns based on microseismic monitoring. Arab. J. Sci. Eng., 2018, 43, 1709-1719.

14. Waltham, T., Park, H. D., Suh, J., Yu, M. H., Kwon, H. H. and Bang, K. M., Collapses of old mines in Korea. Eng. Geol., 2011, 118, 29-36. 
15. Hu, J. Y., Li, S. L., Lin, F., Peng, F. H., Yang, S. and Yu, Z. F., Research on disaster monitoring of overburden ground pressure and surface subsidence in extra-large mined-out area. Rock Soil Mech., 2014, 4, 1117-1122.

16. Wang, Y. M., Lu, Y. G. and Sun, G. Q., Study on the law of rock movement and surface subsidence by deep mining with sublevel caving. Met. Mine., 2015, 6, 6-9.

17. Zheng, H. C., Song, C. Y., Hu, L., Xiao, G., Li, M. and Zhang, X. J., Simulation of air shock waves induced by large-scale roof caving in huge mined out area. J. Univ. Sci. Technol. Beijing, 2010, 3, 277-281+3.

18. Carter, T. G., Guidelines for use of the scaled span method for surface crown pillar stability assessment. In Proceedings of 1 st International Conference on Applied Empirical Design Methods in Mining, Lima-Perú, 9-11 June 2014, pp. 1-34.

19. Zhang, M. S., Zhu, W. C., Hou, Z. S. and Guo, X. Q., Numerical simulation for determining the safe roof thickness and Critical Goaf Span. J. Min. Saf. Eng., 2012, 4, 543-548.

20. Garrard, G. F. G. and Taylor, R. K., Collapse mechanisms of shallow coal-mine workings from field measurements. Geol. Soc. Eng. Geol. Spec. Publ., 1988, 25, 181-192.

21. Kratzsch, H., Mining Subsidence Engineering, Springer-Verlag, Berlin, Heidelberg, New York, 1983, pp. 58-59.

22. Sainsbury, B., Pierce, M. and Mas Ivars, D., Analysis of caving behaviour using a synthetic rock mass-ubiquitous joint rock mass modelling technique. In Proceedings of the 1st Southern Hemisphere International Rock Mechanics Symposium (SHIRMS), 2008, pp. 243-253.

23. Terzaghi, K., Theoretical Soil Mechanics, John Wiley and Sons, New York, 1943.

24. Duplancic, P., Characterization of caving mechanisms through analysis of stress and seismicity. Unpublished $\mathrm{Ph} D$ thesis, Department of Civil and Resource Engineering, University of Western Australia, 2002, p. 227.

25. Cai., M., Kaiser, P. K. and Uno, H., Estimation of rock mass deformation modulus and strength of jointed hard rock masses using the GSI system. Int. J. Rock Mech. Min. Sci., 2004, 41(1), 3-19.

26. $\mathrm{Hu}, \mathrm{S} . \mathrm{M}$. and $\mathrm{Hu}, \mathrm{X}$. W., Estimation of rock mass parameters based on quantitative GSI system and Hoek-Brown criterion. Rock Soil Mech., 2011, 32, 861-866.

27. Hoek, E., Carter, T. G. and Diederichs, M. S., Quantification of the geological strength index chart. In 47th US Rock Mechanics/Geomechanics symposium, San Francisco, USA, 23-26 June 2013, p. 8.

28. Hoek, E., Carranza-Torres, C. T. and Corkum, B., Hoek-brown failure Crition, 2002 Edition, Ion Proceedings of Narms-tac Conference, Toronto, 2002, 1, 267-273.

ACKNOWLEDGEMENT. The authors wish to acknowledge the contributions of Prof. S. K. Satheesh in reviewing a draft of this paper and in participating in the development of crown pillar caving of the minedout area.

Received 16 August 2018; revised accepted 10 October 2018

doi: $10.18520 / \mathrm{cs} / \mathrm{v} 116 / \mathrm{i} 4 / 654-660$

\section{Estimation of regional groundwater discharge and baseflow contribution in northern stretch of the Yamuna River system of Delhi}

\author{
Aryaman Jain ${ }^{1, *}$ and Shashank Shekhar ${ }^{2}$ \\ ${ }^{1}$ Delhi Technological University, Delhi 110 042, India \\ ${ }^{2}$ Department of Geology, University of Delhi, Delhi 110 007, India
}

Urban agglomerations in India of late have started facing drinking and domestic water scarcity. The city state of Delhi has witnessed accelerated urbanization and an exponential growth in population. In this context, it is desired to locate sustainable groundwater resources in Delhi. This communication examines the northern stretch of the Yamuna floodplain system in Delhi with respect to source sustainability. An aquifer can sustain extensive exploitation only if it is replenished regularly. Though the river floodplain system gets recharged by monsoon flooding, the recharged water may not sustain the source aquifer until the end of summer. Thus before exploitation all floodplains have to be examined vis-à-vis regional groundwater dynamics. In this context it was found that the floodplain system in the northern stretch of River Yamuna receives considerable regional groundwater flow. Some of this also contributes to river flow. The present study has estimated regional groundwater flow in this aquifer stretch of the Yamuna river system as $10,513,460 \mathrm{~m}^{3} / \mathrm{yr}(\sim 11 \mathrm{MCM} / \mathrm{yr})$. Besides, the yearly baseflow contribution to the Yamuna in the study area has been estimated as $518,472 \mathrm{~m}^{3} / \mathrm{yr}$ ( $0.5 \mathrm{MCM} / \mathrm{yr})$.

Keywords: Baseflow, flownets, floodplain, regional groundwater discharge, river system.

THE city state of Delhi has witnessed overexploitation of groundwater resources and fast depletion in groundwater reserves in majority of the aquifer systems ${ }^{1-3}$. The Yamuna, a perennial river, flows from north to south through Delhi (Figure 1).

The Yamuna floodplain in Delhi consists of a layer of younger (or newer) alluvium over an older alluvium ${ }^{2-4}$. The thickness of the younger alluvium layer varies from $70 \mathrm{~m}$ in North Delhi to $30 \mathrm{~m}$ in South Delhi ${ }^{4}$. The younger alluvium is an unconfined aquifer ${ }^{5-8}$. The specific yield of this aquifer had been estimated as 0.2 (refs 4, 6, 8, 9).

In the present study, groundwater flow to the Yamuna floodplain was estimated using a flownet construction. In such analysis of groundwater flow, water table contours represent equipotential lines and flow lines indicating the direction of groundwater flow are perpendicular to these

*For correspondence. (e-mail: shashankshekhar01@gmail.com; aryamanjain.aj@gmail.com) 